\title{
Cervical Cancer Screening: Knowledge, Participation and Associated Factors among Women in the Dantokpa Market in Benin
}

\author{
Badirou Aguemon,", Barikissou Georgia Damien², Charles Jérôme Sossa ${ }^{3}$, \\ Sètondji Géraud Roméo Padonou ${ }^{1}$, Mondukpè Jennifer Marie-Géraud Olofindji ${ }^{1}$
}

\author{
${ }^{1}$ Department of Public Health, Faculty of Health Sciences, University of Abomey-Calavi, Cotonou, Republic of Benin \\ ${ }^{2}$ Population and Health Department, Center for Training and Research in Population, University of Abomey-Calavi, Cotonou, Republic \\ of Benin \\ ${ }^{3}$ Regional Institute of Public Health, University of Abomey-Calavi, Ouidah, Republic of Benin
}

Received April 16, 2021; Revised May 17, 2021; Accepted July 19, 2021

\section{Cite This Paper in the following Citation Styles}

(a): [1] Badirou Aguemon, Barikissou Georgia Damien, Charles Jérôme Sossa, Sètondji Géraud Roméo Padonou, Mondukpè Jennifer Marie-Géraud Olofindji, "Cervical Cancer Screening: Knowledge, Participation and Associated Factors among Women in the Dantokpa Market in Benin," Universal Journal of Public Health, Vol. 9, No. 4, pp. 163 172, 2021. DOI: 10.13189/ujph.2021.090401.

(b): Badirou Aguemon, Barikissou Georgia Damien, Charles Jérôme Sossa, Sètondji Géraud Roméo Padonou, Mondukpè Jennifer Marie-Géraud Olofindji (2021). Cervical Cancer Screening: Knowledge, Participation and Associated Factors among Women in the Dantokpa Market in Benin. Universal Journal of Public Health, 9(4), 163 - 172. DOI: 10.13189/ujph.2021.090401.

Copyright $\odot 2021$ by authors, all rights reserved. Authors agree that this article remains permanently open access under the terms of the Creative Commons Attribution License 4.0 International License

\begin{abstract}
Introduction: Cervical cancer is an important public health issue worldwide and the number of cervical cancer is increasing in Benin country. The study aimed to evaluate the level of knowledge and degree of participation of women with regard to screening, as well as the factors associated with it. Methods: A cross-sectional survey was conducted between August and September 2020. A sample of 474 women was selected by three-stage cluster sampling. The women selling in the Dantokpa market, aged 25 to 65 were interviewed. Results: The mean age of the women was 40.20 years \pm 10.66 . The mean score for knowledge level about cervical cancer was $3.01 \pm 2.77$ and that for knowledge level about screening was $2.72 \pm 3.07$. The family history of gynecological cancers ( $p<0.0001)$, the level of knowledge about cervical cancer $(p<0.0001)$, and the level of knowledge about cancer screening $(\mathrm{p}<0.0001)$ were significantly associated with the practice of screening. Conclusion: In order to increase the use of cervical cancer screening by market women, it is necessary to carry out large information campaigns to improve the level of knowledge of women in the market on the disease development and benefice of screening.
\end{abstract}

Keywords Cervical Cancer, Knowledge, Screening Practice, Benin, Dantokpa Market Women

\section{Introduction}

Cervical cancer (CC) is a worldwide public health problem. Its incidence continues to rise each year. CC is the fourth most common cancer among women globally, with an estimated 570,000 new cases in 2018 . Nearly $90 \%$ of the 311,000 deaths worldwide in 2018 occurred in low and middle-income countries $[1,2]$. Women who die of $\mathrm{CC}$, especially in developing countries, are in the prime of their lives. According to WHO, CC will kill more than 443,000 women a year worldwide by 2030 without screening; more than $98 \%$ of these deaths will occur in developing countries, of which $90 \%$ will occur in sub-Saharan Africa [3]. CC control includes primary prevention by vaccination against Human Papilloma Virus in adolescent girls who have not yet started a sexual activity, secondary prevention by screening and treatment 
of pre-cancerous lesions, and tertiary prevention by diagnosis and treatment of invasive $\mathrm{CC}$, and palliative care $[1,3]$.

$\mathrm{CC}$ ranks second among the most frequent cancers over the past five years with a prevalence of $16.8 \%$ in Benin [4]. The high toll of CC is due to the fact that the majority of cases are detected in late stages as a result of its ignorance by the majority of populations at risk, limited access to prevention programs, treatment services, and resources.

In Benin, actions carried out to control $\mathrm{CC}$ are mostly free screening and awareness campaigns carried out occasionally within the framework of International Women's Day by foundations and other civil organizations, each acting on its side. In addition, these crusades last only four days most of the time. They do not specifically take into account certain categories of population, in particular, less education and low socioeconomic people. In Benin, the various studies on cancers deal more with biomedical and therapeutic aspects. Thus, the present study was addressed to less education and low economic women. It was addressed to women selling at Dantokpa market (the largest market in Benin). The socio-demographic characteristics and the gynecological and obstetrical profile of women will be described, and the factors linked to the practice of screening among the women will be identified.

\section{Methods}

\section{Study Area}

Dantokpa market is located in Cotonou (the economic capital) in the south of Benin country. It consists of a large main building on three levels ( 66 by 44 meters) and is subdivided into several compartments. The fame of the market is sub-regional or even international since many traders from West and Central Africa meet on this large business platform. Dantokpa is subdivided into eight activity areas namely: Dadonou-sodji (sofladoto), a condiment sales area; Singbodji (Avo-sodji): fabric sales area; Singboglouè: miscellaneous sales area; Noukoukou-sodji: herbal tea sales area; Gbogbanou: Tokpa radio area; Missèbo: area for selling second-hand clothes; Pièce-sodji: spare parts sales area; and Djinounkoun-sodji: foodstuffs sales area. Each activity area is subdivided into several aisles (more than five). Each aisle was structured in two rows. Several fixed places or shops are located in each row. According to statistics from the Société de Gestion des Marchés Autonomes du Bénin (SOGEMA) in 2016, Dantokpa has 16,406 fixed places (shops, baits, hangars, boxes and kiosks). Most of the vendors in Dantokpa are women. They are specialized in all types of trades, foods, and agro-industries.

Generally, the users (male and female) of the Dantokpa market had a level of education below primary school (60\%) and a low socio-economic level (73\%) [5]. 27\% of female vendors have never been to school [6].

\section{Population and Study Design}

A cross-sectional study was carried out from August 2, 2020 to September $31^{\text {st }}, 2020$ among women in the Dantokpa market.

The inclusion criteria were: i) to be a woman trader in the market, ii) belonging to be 25 to 65 age group, and ii) and gave verbal consent. The exclusion criteria were: i) women with gynecological cancer (uterus and appendix), ii) have undergone a total hysterectomy, and iii) have refused to participate in the survey.

\section{Sampling}

A three-stage cluster sampling was done. The first degree was represented by the activity zone, the second degree was the aisle (corridor) within the activity zone and the third degree was the shop.

\section{Sample Size}

The sample size was calculated from Schwartz formula: $\mathrm{n}=\left(\varepsilon^{2} \mathrm{pq} / \mathrm{i}^{2}\right)^{* 2}$. $\varepsilon$, a reduced deviation for a risk equal to $5 \%$, was equal to 1.96; $\mathrm{p}$ was the probability of occurrence of $\mathrm{CC}$, for that we used the prevalence of $\mathrm{CC}$ in Benin $(\mathrm{p}=16.8 \%)$ [4]; q was equal to $1-\mathrm{p}$; $\mathrm{i}$ was a desired precision (i was equal to 0.05 ); and $\mathrm{k}$ was a cluster effect equal to 2 .

The sample size was $n=430$. With an estimated margin of error of $10 \%$, the total population to be surveyed was $n$ $=473$.

\section{Sampling Technique}

Three-stage random selection was done. In the first degree, five activity areas out of the eight were selected by simple randomization. In the second stage, five aisles were selected in each selected activity area by simple randomization. A total of 25 aisles were paced in the five selected activity areas. Finally, in the third degree, the shops were randomly selected. Only one woman present at the time of the survey was selected by the shop gradually until the expected number was reached. If there were no women in a shop, the next shop was selected.

\section{Data Collection Technique and Tools}

Data were collected by using a questionnaire. The questions were addressed to the women by using the face-to-face technique.

\section{Variables}

The dependent variable of this study is the screening 
participation (the practice of screening), classified into two categories (Yes: for women who have been screened at least once, and No: for women who have never been screened).

The independent variables were socio-demographic variables (age, marital status, education level, religion, monthly income, etc.); gynecology and obstetrics variables (parity, history of miscarriages; history of cesarean section; use of hormonal contraceptives; experience of genital infections during the last 12 months; gynecological follow-up (consultation with a gynecologist during the last 12 months or the past 3 years; family history of gynecological cancer). Variables related to CC knowledge were also taken into account. This information allowed us to calculate the knowledge score on CC. Each correct answer is assigned 1 and a false one 0 . The knowledge score is equal to the sum of the grades credited to each item and is rated from 0 to 9 .

The women were classified according to their knowledge level in the following categories:

"No knowledge": score $=0$.

"Low knowledge": score between 1-3 grades

"Average knowledge" corresponding to a score between 4 and 6 grades

"Good knowledge" corresponding to a score greater than 6 grades

The knowledge about screening was also assessed. It concerned the knowledge of screening possibilities; the place of performance; the age to start screening; the professionals qualified to do so; and the cost.

This information allowed us to calculate the knowledge score on CC screening. Each correct answer was assigned 1 and the false answer was assigned 0. The knowledge score is equal to the sum of the points assigned to each item and is rated from 0 to 13 . The women were classified according to their level of knowledge in the following categories:

"No knowledge": score $=0$

"Low knowledge": score 1-4 grades

"Average knowledge" corresponding to a score between 5 and 8 grades

"Good knowledge" corresponding to a score greater than 8 grades.

\section{Data Management and Statistical Analysis}

SPSS version 18 software was used for data encoding and analysis. The socio-demographic characteristics, the gynecological and obstetrical profile of the respondents, the frequency of screening, the level of knowledge of women about $\mathrm{CC}$, and their level of knowledge about screening were described. A bivariate analysis was performed using statistical tests including the chi-square test to compare percentages and the student test to compare means. For multivariate analysis, all variables with a p-value $\leq 20 \%$ during bivariate analysis were introduced into a logistic regression model. The significance level was $\mathrm{p}<0.05$.

\section{Results}

A total of 478 women aged 25 to 65 were enrolled in the study. 474 women completed the survey. Four people were eliminated for inconsistent responses.

\section{Socio-demographic Characteristics}

The mean age of the respondents was $40.21 \pm 10.66$ years old. The youngest was 25 years old and the oldest was 65 years old. People aged 25 to 35 were the most represented (38\%). Married women represented $75.70 \%$ of the study population. Table 1 summarizes the information related to socio-demographic characteristics.

\section{Women's Gynecological and Obstetrical Profile}

More than $70 \%$ of the women were multiparous. Most of them had neither a history of miscarriages $(84.20 \%)$ nor a family history of gynecological cancer (86.30\%). $10 \%$ of women had a genital infection in the past 12 months. As for gynecological follow-up, $80.40 \%$ of respondents had not benefited from it during the past 12 months. Table 2 shows the gynecological and obstetrical profiles of the respondents. 
Table 1. Women distribution according socio-demographical characteristics, Dantokpa market, Cotonou, 2020

\begin{tabular}{|c|c|c|}
\hline $\begin{array}{l}\text { Percentage distribution of women according to socio-demographic } \\
\text { characteristics }\end{array}$ & $\mathbf{n}$ & Percentage $(\%)$ \\
\hline \multicolumn{3}{|l|}{ Marital status } \\
\hline Single & 60 & 12.70 \\
\hline Married & 359 & 75.70 \\
\hline Divorced & 21 & 4.40 \\
\hline Widow & 34 & 7.20 \\
\hline \multicolumn{3}{|l|}{ Education level } \\
\hline Not schooled & 155 & 32.70 \\
\hline Primary/secondary & 285 & 60.10 \\
\hline Higher level & 34 & 7.20 \\
\hline \multicolumn{3}{|l|}{ Ethnic group } \\
\hline Fon & 191 & 40.30 \\
\hline Goun & 87 & 18.40 \\
\hline Yoruba/Nago & 105 & 22.10 \\
\hline Mahi & 37 & 7.80 \\
\hline Adja/Mina & 16 & 3.30 \\
\hline Others & 38 & 8.00 \\
\hline \multicolumn{3}{|l|}{ Religion } \\
\hline Christian & 354 & 74.70 \\
\hline Muslim & 103 & 21.70 \\
\hline Traditional & 3 & 0.60 \\
\hline None & 14 & 3.00 \\
\hline \multicolumn{3}{|l|}{ Place of residence } \\
\hline Cotonou & 317 & 66.90 \\
\hline Outside of Cotonou & 157 & 33.10 \\
\hline \multicolumn{3}{|l|}{ Monthly income (Fcfa) } \\
\hline$<40.000$ & 115 & 24.30 \\
\hline$\geq 40.000$ & 359 & 75.70 \\
\hline
\end{tabular}

Table 2. Women's distribution according to gynecological and obstetrical profile, Dantokpa market, Cotonou, 2020

\begin{tabular}{|c|c|c|}
\hline $\begin{array}{c}\text { Percentage distribution of women according to socio-demographic } \\
\text { characteristics }\end{array}$ & $\mathbf{n}$ & Percentage $(\%)$ \\
\hline \multicolumn{3}{|l|}{ Parity } \\
\hline Nulliparous & 35 & 7.40 \\
\hline Primiparous & 93 & 19.60 \\
\hline Multiparous & 346 & 73.00 \\
\hline \multicolumn{3}{|l|}{ History of miscarriage } \\
\hline Yes & 75 & 15.80 \\
\hline No & 399 & 84.20 \\
\hline \multicolumn{3}{|l|}{ History of caesarean section } \\
\hline Yes & 91 & 19.20 \\
\hline No & 383 & 80.80 \\
\hline \multicolumn{3}{|l|}{ Hormonal contraceptives use } \\
\hline Yes & 120 & 25.30 \\
\hline No & 354 & 74.70 \\
\hline \multicolumn{3}{|l|}{ Genital infections in the past months } \\
\hline Yes & 52 & 11.00 \\
\hline No & 422 & 89.00 \\
\hline \multicolumn{3}{|l|}{ Gynaecological follow-up over the last 12 months } \\
\hline Yes & 69 & 14.60 \\
\hline No & 405 & 85.40 \\
\hline \multicolumn{3}{|l|}{ Gynaecological follow-up over the last three years } \\
\hline Yes & 126 & 26.60 \\
\hline No & 348 & 73.40 \\
\hline \multicolumn{3}{|l|}{ Family history of gynaecological cancer } \\
\hline Yes & 51 & 10.76 \\
\hline No & 423 & 89.24 \\
\hline
\end{tabular}


Table 3. Life-experience of women already screened cervical cancer, Dantokpa market, Cotonou, 2020

\begin{tabular}{|c|c|c|}
\hline Percentage distribution of women according to life-experience & $\mathbf{n}$ & Percentage $(\%)$ \\
\hline \multicolumn{3}{|l|}{ Screening cost } \\
\hline Free & 10 & 45.50 \\
\hline Paid & 12 & 54.54 \\
\hline \multicolumn{3}{|l|}{ Cost of screening acceptability } \\
\hline Yes & 2 & 9.10 \\
\hline No & 9 & 40.90 \\
\hline No answer & 11 & 50.00 \\
\hline \multicolumn{3}{|l|}{ Satisfaction with the reception } \\
\hline Yes & 21 & 95.45 \\
\hline No & 1 & 4.55 \\
\hline \multicolumn{3}{|l|}{ Time spent at the centre for screening } \\
\hline Less than half hour & 12 & 54.54 \\
\hline Half hour-one hour & 7 & 31.82 \\
\hline More than one hour & 3 & 13.64 \\
\hline \multicolumn{3}{|l|}{ Satisfaction with the progress of the screening } \\
\hline Yes & 19 & 86.36 \\
\hline No & 3 & 13.64 \\
\hline \multicolumn{3}{|l|}{ Painful during the screening } \\
\hline Yes & 6 & 27.27 \\
\hline No & 16 & 72.73 \\
\hline \multicolumn{3}{|l|}{ Troublesome during screening } \\
\hline Yes & 10 & 45.46 \\
\hline No & 12 & 54.54 \\
\hline \multicolumn{3}{|l|}{ Bleeding after the screening } \\
\hline Yes & 10 & 45.46 \\
\hline No & 12 & 54.54 \\
\hline \multicolumn{3}{|l|}{ Result deadline } \\
\hline Less than a week & 10 & 45.46 \\
\hline A week & 6 & 27.27 \\
\hline Two weeks & 6 & 27.27 \\
\hline Three weeks and over & 0 & 0.00 \\
\hline
\end{tabular}

\section{Screening Practice and Lives of Women already been Screened for Cervical Cancer}

Of the 474 women who had already been screened, $4.64 \%$ $(\mathrm{n}=22)$ were screened at least once for CC. Among them, $16(73 \%)$ were carried out less than five years ago. For more than half of the women $(54.54 \%)$ the screening was not free. For most of them $(40.90 \%)$, the cost of screening was not acceptable. Most of the women had been seen by a midwife or gynecologist after the screening results. More than $80 \%$ of them had received an explanation of their result and said they were ready to have another screening if necessary. Table 3 shows the experiences of women who have already been screened for CC.

\section{Women's Knowledge about Cervical Cancer}

$30.17 \%$ of women had no knowledge, $28.48 \%$ had low knowledge, $24.26 \%$ had intermediate knowledge and $17.09 \%$ have good knowledge of CC disease. More than half of the respondents $(59.90 \%)$ knew the existence of CC. $67.90 \%$ of women were unaware of CC; $11 \%$ thought that $\mathrm{CC}$ could appear as early as the age of 30 . More than $70 \%$ of women were unaware of the existence of means of preventing CC (Table 4). 
Table 4. Women's knowledge in cervical cancer, Dantokpa market, Cotonou, 2020

\begin{tabular}{|c|c|c|}
\hline Percentage distribution of women according to knowledge in cervical cancer & $\mathbf{n}$ & Percentage $(\%)$ \\
\hline \multicolumn{3}{|l|}{ Cervical cancer existence } \\
\hline Yes & 284 & 59.90 \\
\hline No & 72 & 15.20 \\
\hline Do not know & 118 & 24.90 \\
\hline \multicolumn{3}{|l|}{ Knowledge at least one risk factor } \\
\hline Yes & 133 & 28.10 \\
\hline No & 341 & 71.90 \\
\hline \multicolumn{3}{|l|}{ Knowledge at least one symptom } \\
\hline Yes & 99 & 20.90 \\
\hline No & 375 & 79.10 \\
\hline \multicolumn{3}{|l|}{ Women at risk for cervical cancer } \\
\hline $\mathrm{SAW}^{*}$ & 2 & 0.40 \\
\hline SIW** & 121 & 25.50 \\
\hline Menopaused women & 40 & 8.40 \\
\hline All women & 58 & 12.20 \\
\hline Do not know & 253 & 53.37 \\
\hline \multicolumn{3}{|l|}{ Cervical cancer age prevalence (years) } \\
\hline 25 & 47 & 9.90 \\
\hline 30 & 52 & 11.00 \\
\hline 40 & 19 & 4.00 \\
\hline 50 and over & 34 & 7.17 \\
\hline Do not know & 322 & 6.93 \\
\hline \multicolumn{3}{|l|}{ Cervical cancer treatment } \\
\hline $\begin{array}{l}\text { Yes } \\
\text { No }\end{array}$ & $\begin{array}{l}189 \\
285\end{array}$ & $\begin{array}{l}39.90 \\
60.10\end{array}$ \\
\hline $\begin{array}{c}\text { Healing possibility } \\
\text { Yes } \\
\text { No }\end{array}$ & $\begin{array}{l}154 \\
320\end{array}$ & $\begin{array}{l}32.50 \\
67.50\end{array}$ \\
\hline $\begin{array}{c}\text { Cervical cancer lethality } \\
\text { Yes } \\
\text { No }\end{array}$ & $\begin{array}{l}269 \\
205\end{array}$ & $\begin{array}{l}56.80 \\
43.20\end{array}$ \\
\hline \multicolumn{3}{|l|}{ Existence of cervical cancer prevention's means } \\
\hline $\begin{array}{l}\text { Yes } \\
\text { No }\end{array}$ & $\begin{array}{l}129 \\
345\end{array}$ & $\begin{array}{l}27.20 \\
72.80\end{array}$ \\
\hline
\end{tabular}

*SAW: sexually active women; ** SIW: sexually inactive women.

\section{Women's knowledge about cervical cancer screening}

$47.04 \%$ of women have no knowledge, $17.30 \%$ had low knowledge, $32.91 \%$ had intermediate knowledge and $2.74 \%$ have good knowledge of $\mathrm{CC}$ disease. The majority of women $(70 \%)$ did not know any health care center where it is possible to be tested. $77.63 \%$ of the study population did not know if the pregnant woman was suitable for screening. More than $70 \%$ of the respondents did not know what age to start screening for $\mathrm{CC}$.

\section{Socio-demographic and obstetric factors associated with screening practice}

In the bivariate analysis, the following variables were significantly associated with the practices of screening: education level $(p<0.0001)$, place of residence $(p=0.0080)$, and monthly income $(\mathrm{p}=0.0070)$. There is also a significant relationship between screening practice and genital infections during the last 12 months ( $\mathrm{p}=0.0010)$, gynecological follow-up during the last 12 months $(\mathrm{p}<0.0001)$, the family history of cancer, gynecological $(p<0.0001)$, gynecological follow-up over the past 3 years $(\mathrm{p}=0.0570)$, (Table 5).

The bivariate analysis with the different knowledge scores revealed that: the level of knowledge of women about $\mathrm{CC}$ was significantly associated with the screening practice $(p<0.0001)$; the level of knowledge of women about CC screening was significantly associated with screening practice $(\mathrm{p}<0.0001)$. The mean CC knowledge score was therefore significantly higher in women who had screened at least once than in others, 7.09 versus 2.75 . The same is true for the mean knowledge score for CC 
screening, which was significantly higher among those who have already performed it, 8.14 versus 2.43 .

In multivariate analysis, the family history of gynecological cancers $(\mathrm{OR}=16.44 \quad$ [2.51-107.90], $\mathrm{p}=0.0040)$, the knowledge score on $\mathrm{CC}, \quad(\mathrm{OR}=2.41$
[1.12-5.19], $\mathrm{p}=0.0250)$ and the knowledge score on screening $\quad(\mathrm{OR}=3.02 \quad[1.71-5.36], \quad \mathrm{p}<0.0001) \quad$ were significantly associated on screening practice adjusted on gynecological follow-up in the last 12 months and level of education (Table 6).

Table 5. Socio-demographical and obstetrical factors associated with women screening, bivariate analysis, Dantokpa market, Cotonou, 2020

\begin{tabular}{|c|c|c|c|}
\hline \multirow{2}{*}{$\begin{array}{l}\text { Percentage distribution of women according to socio-demographic } \\
\text { characteristics }\end{array}$} & \multicolumn{2}{|c|}{ Screening practice (n) } & \multirow[t]{2}{*}{ p-value } \\
\hline & Yes & No & \\
\hline Education level & & & $<0.0001$ \\
\hline Not schooled & 2 & 153 & \\
\hline Primary/secondary & 12 & 273 & \\
\hline Higher & 8 & 26 & \\
\hline Place of residence & & & 0.0080 \\
\hline Cotonou & 9 & 308 & \\
\hline Periphery of Cotonou & 13 & 144 & \\
\hline Monthly income (FCFA) & & & 0.0070 \\
\hline$<40.000$ & 0 & 115 & \\
\hline$\geq 40.000$ & 22 & 337 & \\
\hline Genital infections over the 12 past months & & & 0.0010 \\
\hline Yes & 7 & 45 & \\
\hline No & 15 & 407 & \\
\hline Gynecological follow-up over the 12 past months & & & $<0.0001$ \\
\hline Yes & 15 & 54 & \\
\hline No & 7 & 398 & \\
\hline Cervical cancer family history & & & $<0.0001$ \\
\hline Yes & 10 & 41 & \\
\hline No & 12 & 411 & \\
\hline
\end{tabular}

Table 6. Socio-demographical and obstetrical factors associated with women screening practices, multivariate analysis, Dantokpa market, Cotonou, 2020

\begin{tabular}{ccc}
\hline Variables & \multicolumn{2}{c}{ Screening practice } \\
\cline { 2 - 3 } & OR [CI at 95\%] & p-value \\
\hline Gynecological follow-up over the past 12 months & $4.55[0.94-21.90]$ & 0.0590 \\
Family history of gynaecological cancers & $16.44[2.51-107.90]$ & 0.0040 \\
Level of knowledge about cervical cancer & $2.41[1.12-5.19]$ & 0.0250 \\
Screening knowledge score & $3.02[1.71-5.36]$ & $<0.0001$ \\
Education level & $4.45[0.93-21.19]$ & 0.0600 \\
\hline
\end{tabular}




\section{Discussion}

The study aimed at evaluating the level of knowledge and degree of participation of women with regard to screening and associated factors. Of the respondents, $17.09 \%$ had good knowledge about CC and $2.74 \%$ had good knowledge about CC screening. $4.64 \%$ of women were screened at least once for $\mathrm{CC}$. The family history of gynecological cancers, the knowledge score on $\mathrm{CC}$, and the knowledge score on screening were significantly associated with screening practices.

\section{Dantokpa Market'S Women Screening for Cervical Cancer}

The screening prevalence in our study population is very low and similar to those, reported by Dakenyo et al. in Cameroon in 2018 (7.41\%) [7]. Ilboudo in Burkina and Gakou in Senegal found a better level of CC screening prevalence than ours respectively of $20.22 \%[8,9]$ and $28 \%$ [10]. The low prevalence found in the study could be explained by the lack of targeting of mass screening campaigns organized for women. Among the women who did the screening, most of them $(68.18 \%)$ were motivated by a health worker and $81.81 \%$ would recommend screening to beloved. Dakenyo et al. came to the same conclusion. He reported that $75 \%$ of women underwent screening because they were motivated by a health worker [7]. As for recommending screening to beloved, a study conducted by Ilboudo found that $98.20 \%$ of respondents would agree to recommend screening to beloved [9].

\section{Screening Practice And Barriers of Screening for Cervical Cancer}

Several factors can affect a woman's ability and desire to participate in CC prevention programs. It is essential to identify the reasons that prevent a woman from using the services in the context of implementing a successful program $[11,12]$. In the current study, the reasons for not getting the screening test done can be the screening cost, the time spent at the centre for screening, troublesome during screening, and bleeding after the screening.

\section{Cervical Cancer Knowledge and Screening}

Among the surveyed women, 59.90\% had already heard of CC. Belkheyr, in Algeria, found a lower result (42.43\%) in 2014 [13]. Compaore et al, in 2016 noted that more than $90 \%$ of respondents had heard of CC [14]. Gakou found $82 \%$ in a study in Dakar in 2018 [10]. However, a large number of our respondents $(71.90 \%)$ did not know any risk factors. The differences observed between these various studies could be linked to the variability of the socio-demographic profile of the women included in each study. Geremew et al. in Ethiopia in 2018, also found a low percentage of women with knowledge of CC [15].
The level of knowledge about screening is also low with an average score of 2.72 (3.07) [scale from 0 to 13]. A similar result was found by Ilboudo in Burkina Faso. The women had poor knowledge with an average score of 4.31 points \pm 2.55 out of 11 [9].

These results suggest that there is a real need for sensitization on CC. It is, therefore, necessary to continue and intensify awareness-raising and information campaigns for women on this disease.

\section{Factors Associated with Screening Practice}

During bivariate analysis, monthly income was statistically associated with the practice of screening. According to the literature, screening is less likely among low-income women: they are therefore more at risk of developing CC [1-3, 16, 17]. Usually, women face difficulties related not only to the cost of screening but also to the related costs that arise during screening. These difficulties explain why women with a low socioeconomic level are reluctant to be tested. In Benin, as in several other countries, mass screening is organized during campaigns where screening is very low cost or even free. But these are not permanent strategies. Such public health actions should be encouraged in order to allow a greater number of women to adopt CC screening. Family history of gynecological cancers, the level of knowledge about $\mathrm{CC}$, and the level of knowledge about screening for CC, are the main factors associated with the practice of screening. In Kenya, Rosser et al. found a strong relationship between the practice of screening and the level of knowledge of the disease [18]. The association between gynecological follow-up $(\mathrm{p}=0.0590)$ and the screening practice was not significant even if the number of people performing the screening was clearly higher in the group of those who undergo gynecological follow-up compared to others.

Our results are consistent with those of other authors. In fact, according to a study carried out in the Val-d'Oise department in France, women having a gynecological consultation every year had a $90 \%$ chance of having had a cervico-uterine smear [19]. Furthermore, a study report showed in 2014 that the lack of screening in women in Ile-de-France was significantly associated with contributing factors such as gynecological follow-up [16, 17]. The same authors have shown that women who have never been enrolled in or having an equal level of education at primary or secondary level were less screened than women with higher education. This trend is also observed in our study even though the association between the education level and the screening practice was not significant $(p=0.0600)$ in the final model. According to the WHO, health education should ensure that women, their families, and the community understand that $\mathrm{CC}$ is preventable. Health education messages about CC should also be consistent with national policy, 
culturally appropriate, and consistent across different levels of the health system [20].

\section{Study Limitations}

A simple random selection of all respondents would have been more accurate and would have covered the entire market but the full list of female users was not available. In addition, the survey could be combined with a mass screening of the target population.

\section{Conclusions}

The study showed that a low rate of completion of $\mathrm{CC}$ screening was linked to family history of gynecological cancers, the level of knowledge about $\mathrm{CC}$ and the level of knowledge about screening for CC. Improving and strengthening women's knowledge of $\mathrm{CC}$ and related screening can increase their participation in screening. Intervention on $\mathrm{CC}$ prevention in Benin must prioritize education and information for women while facilitating easier financial accessibility. Women of the Dantokpa market need frequent awareness sessions and a regular bi-annual mass screening campaign.

\section{Acknowledgement}

We knowledge all the participants of the study.

\section{Conflict of Interest}

The authors declare that they have no conflict of interests.

\section{REFERENCES}

[1] World Health Organization (WHO). Human papillomavirus (HPV) and cervical cancer: Key facts. WHO. Geneva. 11 November 2020. Accessed on 12/02/2021. Available from: https://www.who.int/en/news-room/fact-sheets/detail/hum an-papillomavirus-(hpv)-and-cervical-cancer.

[2] Ferlay J., Ervik M., Lam F., Colombet M., Mery L., Piñeros M., Znaor A., Soerjomataram I., Bray F., "Global Cancer Observatory: Cancer Today. Lyon, France: International Agency for Research on Cancer". Available from: https://gco.iarc.fr/today (accessed on Mar 13, 2021.

[3] Mboumba Bouassa R.S., Prazuck T., Lethu T., Meye J.F., Belec L., "Cervical cancer in sub-Saharan Africa: an emerging and preventable disease associated with oncogenic human papillomavirus", Médecine et santé Tropicales, vol. 27, no. 1, pp. 16-22, 2017. DOI: $10.1684 / \mathrm{mst} .2017 .0648$
[4] Ministry of Health, Benin. "Integrated strategic plan to fight against non-communicable diseases 2014-2018. Republic of Benin: national program to fight against non-communicable diseases", 2014 https://www.iccp-portal.org/system/files/plans/Benin\%20P lan_strategique_integre_lutte_contre_maladies_non_trans missibles_2014-2018.pdf. (accessed on Sep 9, 2020)

[5] Talimula K., Mizéhoun-Adissoda C., Padonou G., Aguemon B., Barikissou G., Ouendo E., "Facteurs associés à l'obésité au sein d'un groupe d'usagers du marché Dantokpa (Bénin)", Santé Publique, vol. 4, no. 4, pp. 591-602. DOI: 10.3917/spub.194.0591.

[6] Ibrahim M.C., Adébayo A., Mènonli A., Amadou, A.B.I., Rose, M., Vikkey, H.A., and Ayelo P., "Prevalence and Factors Associated High Blood Pressure among Women at the Market of Dantokpa in Benin in 2017", Occupational Diseases and Environmental Medicine, vol. 8, p. 91-98, 2020. DOI: $10.4236 /$ odem.2020.83007.

[7] Dakenyo R.D., Kenfack B., Vogue N., Tsakoue E.F., Ebode M.E., "Cumber SN. Knowledge, attitudes and practices of women of childbearing age with regards to cervical cancer preventive measures in the MIFI health district, Cameroon", The Pan African Medical Journal, vol. 31, pp. 172, 2018. DOI: 10.11604/pamj.2018.31.172.16320.

[8] Ilboudo H., "Barriers to cervical cancer screening among women aged 25-50 years in the commune of Koupèla, Burkina Faso" [Thesis in medicine]. University Saint Thomas d'Aquin/Faculty of medicine, 2016.

[9] Ilboudo A.L., Knowledge of cervical cancer screening and risk perception among women attending health facilities in Ouagadougou, Burkina Faso [Thesis in medicine]. Burkina-Faso: University of Saint Thomas D'Aquin/Faculty of Health Sciences; 2019. Available from: www.labiogene.org/IMG/pdf/these_finale_du_10.pdf (accessed on Mar 13, 2021)

[10] Gakou N.F.B.S., "Knowledge, attitudes and practices of women surveyed on cervical cancer in two regions of Senegal between 2015 and 2016". [Thesis in medicine]. Dakar: University of Cheickh Anta Diop/Faculty of medicine, pharmacy and odontology, 2018.

[11] Bingham A., Bishop A., Coffey P., Winkler J., Bradley J., Dzuba I., Agurto I., "Factors affecting utilization of cervical cancer prevention services in low-resource settings", Salud Publica Mexico, vol. 45, no. pp.:S408-S416, 2003. DOI: 10.1590/s0036-36342003000900015.

[12] Aswathy S., Quereshi M.A., Kurian B., Leelamoni K., Cervical cancer screening: current knowledge \& practice among women in a rural population of Kerala, India. The Indian Journal of Medical Research, vol. 136, no. 2, pp. 205-210, 2012. Available from: https://pubmed.ncbi.nlm.ni h.gov/22960886/ (accessed on Mar, 25, 2021).

[13] Belkheyr C., "Contribution to the study of cervical cancer screening in the Wilaya of Bechar and the detection of HPV by polymerase chain reaction" [Master of Molecular and cellular biology]. Algeria: University of Aboubekr Belkaid Tlemcen. Faculty of Natural and Life Sciences and Earth and Universe Sciences; 2014.

[14] Compaoré S., Ouedraogo C.M.R., Koanda S., Haynatzki G., Chamberlain R.M., Soliman A.S., "Barriers to Cervical Cancer Screening in Burkina Faso: Needs for Patient and 
Professional Education", Journal of Cancer Education, vol.31, no. 4, pp. 760-766, 2016. DOI: 10.1007/s13187-015-0898-9.

[15] Geremew A.B., Gelagay A.A., Azale T., "Comprehensive knowledge on cervical cancer, attitude towards its screening and associated factors among women aged 30-49 years in Finote Selam town, northwest Ethiopia". Reproductive Health, vol. 15, no. 1, pp. 29, 2018. DOI: 10.1186/s12978-018-0471-1.

[16] Benmansour A., Bouhassina S., Tadj A., "Le cancer du col de l'utérus" [Thesis in medicine]. Algeria: University of Aboubekr Belkaid Tlemcen/Faculty of medicine; 2017.

[17] Vuillermoz C., Chauvin P., Vandentorren S., "The use of screening for female cancers in the population without personal housing in Ile-de-France". Report for the Canceropole of Ile-de-France. Paris, The Samusocial Observatory of Paris \& IPLESP, ERES, 2014. Available
from:http://www.iplesp.upmc.fr/eres/files/Rapport_final_a u_Cancropole.pdf (accessed on Apr 4, 2021).

[18] Rosser J.I., Njoroge B., Huchko M.J., Knowledge about cervical cancer screening and perception of risk among women attending outpatient clinics in rural Kenya. International Journal of Gynecology \& Obstetrics, vol. 128, no. 3, pp. 211-215, 2015. DOI: 10.1016/j.ijgo.2014.09.006.

[19] Bernard E., Saint-Lary O., Haboubi L., Le Breton J., "Dépistage du cancer du col de l'utérus : connaissances et participation des femmes". Santé Publique, vol. 3, no. 3; pp. 255-262. DOI: 10.3917/spub.253.0255.

[20] World Health Organization (WHO), "Comprehensive cervical cancer control: a guide to essential practice - 2nd ed. Comprehensive cervical cancer control: a guide to essential practice" - 2nd ed. Geneva: World Health Organization; 2017. Licence: CC BY-NC-SA 3.0 IGO. Available from: https://apps.who.int/iris/bitstream/handle/10665/254713/97 89242548952-fre.pdf (accessed on Mar 25, 2021) 